\title{
Admission test cardiotocography in labour as a predictor of foetal outcome in high risk pregnancies
}

\author{
Anvesha Kumar*, Purshottam Bantaklal Jaju
}

Department of Obstetrics and Gynecology, Shri BM Patil Medical College Hospital and Research Centre, Vijayapur, Karnataka, India

Received: 18 February 2019

Accepted: 22 February 2019

*Correspondence:

Dr. Anvesha Kumar,

E-mail: anveshakumar83@gmail.com

Copyright: (c) the author(s), publisher and licensee Medip Academy. This is an open-access article distributed under the terms of the Creative Commons Attribution Non-Commercial License, which permits unrestricted non-commercial use, distribution, and reproduction in any medium, provided the original work is properly cited.

\begin{abstract}
Background: Continuous fetal heart monitoring in all pregnant women in labour has gained prominence in obstetric practice in the recent years. The aim of this study was to emphasize on the role of admission cardiotocography (CTG) in labour as a predictor of foetal outcome in high risk pregnancies.

Methods: This was a prospective observational study done on 340 high risk patients admitted in labour with a period of gestation of $\geq 37$ weeks. An admission CTG which consists of a 20-minute recording of FHR and uterine contractions was taken and the foetal outcome was correlated with it. The non-parametric Chi-square test was used for statistical calculations and a $\mathrm{p}$ valve of $<0.05$ was considered to designate statistical significance.

Results: The admission CTG was reactive in $69.4 \%$ of all patients, equivocal in $22.2 \%$ and pathological in $8.4 \%$ of the 340 recruited patients. A total of $37.5 \%$ of the patients were post-dated followed by $20.6 \%$ of pregnancy incuded hypertensive patients. The neonatal outcomes in terms of fetal distress, meconium stained liquor, NICU admission were considerably higher in pathological test. The specificity of the test was $53.3 \%$, and the negative predictive was $86.49 \%$.

Conclusions: Admission CTG is a simple, useful screening test and serves as a non-invasive tool in forecasting the adverse foetal outcomes in high risk pregnancies.
\end{abstract}

Keywords: Cardiotocography (CTG), Foetal outcome, High risk pregnancy

\section{INTRODUCTION}

Foetal surveillance during labour is necessary to ensure safe passage of the foetus from an intrauterine to an extra uterine environment with minimum intervention. ${ }^{1}$ The mechanism of labour itself presents as a physiological stress to the fetus. Thus, continuous foetal heart rate (FHR) monitoring in all pregnant women in labour has gained prominence in obstetric practice in the recent years .Intermittent auscultations can measure the baseline FHR but other features such as baseline variability, accelerations, decelerations in response to the uterine contraction remains unappreciated. ${ }^{2}$ Foetal monitoring is essential to identify foetuses at risk for hypoxic injury due to uteroplacental insuffiency .It can prevent neurological injuries such as cerebral palsy. ${ }^{3}$ Thus, electronic fetal monitoring has been widely adopted. ${ }^{4}$

A number of technical breakthroughs occurred in the 20th century that led to development and commercialisation of cardiotocography (CTG) in the 1960's to monitor fetal heart rate and uterine contractions. ${ }^{5}$ The use of CTG as a first line of investigation for both antepartum and intrapartum monitoring has been widely advocated by some authors to decrease the perinatal mortality. ${ }^{6}$ In developing countries economic constraints limit routine 
and continuous monitoring of electronic fetal heart monitoring .In busy labour wards with a few monitors, selection of the patients for continuous monitoring is necessary. ${ }^{7}$

Ingemarsson et al described an alternative method of monitoring FHR during labour to pick the women apparently at risk whose foetuses were compromised on admission or were likely to be compromised in labourAdmission test (AT). ${ }^{8}$ The admission CTG is a short, usually a 20 minute, recording of the FHR immediately after admission to the labour ward. ${ }^{9}$

The main justification for admission CTG is that the uterine contractions during labour decreases the placental circulation; an abnormal tracing indicates a deficiency and hence identifies foetal compromise at an early stage to allow intervention. ${ }^{10}$ The NICE guidelines of 2017 do not recommend admission CTG in low risk women but offers continuous CTG in patients with risk factors. ${ }^{11}$ The aim of this study was evaluate the predictive value of admission CTG at the time of admission in labour and to correlate the results of the admission CTG with perinatal outcome in high risk obstetric cases.

\section{METHODS}

This was a prospective observational study conducted on 340 high risk patients admitted in labour for a period of one year (April 2017 to March 2018) at Shri B. M. Patil Medical College Hospital and Research Centre, Vijaypura, Karnataka, India. The women eligible to join the study had $\geq 37$ weeks of gestation, were in the 1 st stage of labour (spontaneous in onset), singleton fetus with a cephalic presentation and classified as high risk during the time of admission (Table 1).

\section{Table 1: High risk factor groups.}

\begin{tabular}{|l|}
\hline Risk factors \\
Postdated \\
\hline PIH (Pregnancy induced hypertension) \\
\hline PIH with IUGR (intrauterine growth restriction) \\
IUGR (Intrauterine growth restriction) \\
\hline PROM (premature rupture of the membranes) \\
\hline BOH (Bad obstetric history) \\
\hline Oligohydramanios \\
\hline Diabetes \\
\hline
\end{tabular}

\section{Exclusion criteria}

- Women with a period of gestation $\leq 37$ weeks.

- Congential anomaly confirmed by ultrasonography (USG).

- Multiple pregnancies

- Acute hypoxic states (placental abruption, cord prolapse, abnormal lie and needing emergency caesarean section or elective LSCS (lower segment ceaserean section).

On admission, the women's details, age, parity, antenatal care, menstrual and obstetric, medical history were documented followed by a general and physical examination.

A per abdomen and bimanual examination was done to determine the stage of labour, after which an Admission test CTG was taken by a BPL FM 9856 machine. A 20minute tracing of the FHR with uterine contractions was taken with the patient lying in the left lateral position in a room adjacent to the labour room.

The FHR tracing was classified as normal, suspicious or pathological as according to the classification proposed by NICE (National institute of clinical excellence) guidelines 2017. ${ }^{11}$ Patients with a normal reactive test were monitored by intermittent auscultation for 1 minute, every 30 minutes in the 1 st stage of labour and every 5 minutes in the second stage of labour. (Table 2) (Table $3)$.

Table 2: Definition of CTG tracings (NICE guidelines 2017).

\begin{tabular}{|l|l|}
\hline Category & Definition \\
\hline Normal & $\begin{array}{l}\text { An FHR trace in which features are } \\
\text { classified as reassuring. }\end{array}$ \\
\hline Suspicious & $\begin{array}{l}\text { An FHR trace with 1 no reassuring } \\
\text { feature AND 2 reassuring features. }\end{array}$ \\
\hline Pathological & $\begin{array}{l}\text { An FHR trace with 1 abnormal feature } \\
\text { OR 2 no reassuring features. }\end{array}$ \\
\hline
\end{tabular}

Those with suspicious tracings were placed on continuous CTG monitoring.

In patients with a pathological tracing delivery was hastened by operative, instrumental intervention depending upon the stage of labour. Perinatal outcome was assessed in terms of the colour of the liquor, APGAR score, NICU admission and perinatal mortality.

\section{Statistical analysis}

All characteristics were summarized descriptively. For categorical data, the number and percentage were used in the data summaries and diagrammatic presentation. Chisquare $(\chi 2)$ test was used for association between two categorical variables.

If the p-value was $<0.05$, then the results were considered to be statistically significant otherwise it was considered as statistically non-significant. Data were analyzed using SPSS software Version .23.0. and Microsoft office 2007. 
Table 3: Pathological classification proposed by NICE.

\begin{tabular}{|c|c|c|c|}
\hline \multirow{2}{*}{ Description } & \multicolumn{3}{|l|}{ Feature } \\
\hline & $\begin{array}{l}\text { Baseline (beats/ } \\
\text { minute) }\end{array}$ & $\begin{array}{l}\text { Baseline variability } \\
\text { (beats/minute) }\end{array}$ & Declarations \\
\hline Reassuring & 110 to 160 & 5 to 25 & $\begin{array}{l}\text { None or early Variable decelerations with no } \\
\text { concerning characteristics* for less than } 90 \text { minutes }\end{array}$ \\
\hline Non-reassuring & $\begin{array}{l}100 \text { to } 109 \text { or } \\
161 \text { to } 180\end{array}$ & $\begin{array}{l}\text { Less than } 5 \text { for } 30 \text { to } 50 \\
\text { minutes or More than } 25 \\
\text { for } 15 \text { to } 25 \text { minutes }\end{array}$ & $\begin{array}{l}\text { Variable decelerations with no concerning } \\
\text { characteristics* for } 90 \text { minutes or more OR Variable } \\
\text { decelerations with any concerning characteristics* in } \\
\text { up to } 50 \% \text { of contractions for } 30 \text { minutes or more or } \\
\text { Variable decelerations with any concerning } \\
\text { characteristics* in over } 50 \% \text { of contractions for less } \\
\text { than } 30 \text { minutes or Late decelerations in over } 50 \% \text { of } \\
\text { contractions for less than } 30 \text { minutes, with no maternal } \\
\text { or fetal clinical risk factors such as vaginal bleeding or } \\
\text { significant meconium }\end{array}$ \\
\hline Abnormal & $\begin{array}{l}\text { Below } 100 \text { or } \\
\text { Above } 180\end{array}$ & $\begin{array}{l}\text { Less than } 5 \text { for more than } \\
50 \text { minutes or More than } \\
25 \text { for more than } 25 \\
\text { minutes or Sinusoidal }\end{array}$ & $\begin{array}{l}\text { Variable decelerations with any concerning } \\
\text { characteristics* in over } 50 \% \text { of contractions for } 30 \\
\text { minutes (or less if any maternal or fetal clinical risk } \\
\text { factors) or Late decelerations for } 30 \text { minutes (or less if } \\
\text { any maternal or fetal clinical risk factors) or Acute } \\
\text { bradycardia, or a single prolonged deceleration lasting } \\
3 \text { minutes or more }\end{array}$ \\
\hline
\end{tabular}

\section{RESULTS}

Out of the 320 cases majority of the patients were primigravida in the age group of 21 to 25 years. Pathological AT was higher in the age group of 36 to 40 years and patients with a gestational age of 37 to 40 weeks (Table 4). Around $37.5 \%$ of the patients were postdated followed by PIH (20.6\%), PIH with IUGR PROM
(10.6\%), BOH (bad obstetric history patient) were $6.9 \%$. A few patients had multiple risk factors (Table 5) like CPD (cephalopelvic disproportion), anemia and previous LSCS. About $69.4 \%$ of the patients had a "normal "admission test CTG out of which $13.5 \%$ was associated with fetal distress. A higher percentage of fetal distress was observed in the suspicious AT (26.8\%) and the pathological AT showed an alarming fetal distress of $55.6 \%$ (Table 6).

Table 4: Demographic and clinical characteristics.

\begin{tabular}{|c|c|c|c|c|c|c|c|c|}
\hline \multirow{2}{*}{ Age (years) } & \multicolumn{2}{|c|}{ Normal ( $\mathrm{N}=\mathbf{2 2 2})$} & \multicolumn{2}{|c|}{ Suspicious (N=71) } & \multicolumn{2}{|c|}{ Pathological (N=27) } & \multicolumn{2}{|c|}{ Total $(\mathrm{N}=320)$} \\
\hline & $\mathbf{N}$ & $\%$ & $\mathbf{N}$ & $\%$ & $\mathbf{N}$ & $\%$ & $\mathbf{N}$ & $\%$ \\
\hline $17-20$ & 38 & 66.7 & 15 & 26.3 & 4 & 7.0 & 57 & 17.8 \\
\hline $21-25$ & 101 & 75.9 & 22 & 16.5 & 10 & 7.5 & 133 & 41.6 \\
\hline $26-30$ & 40 & 60.6 & 20 & 30.3 & 6 & 9.1 & 66 & 20.6 \\
\hline $31-35$ & 28 & 66.7 & 10 & 23.8 & 4 & 9.5 & 42 & 13.1 \\
\hline $36-40$ & 15 & 68.2 & 4 & 18.2 & 3 & 13.6 & 22 & 6.9 \\
\hline Total & 222 & 69.4 & 71 & 22.2 & 27 & 8.4 & 320 & 100.0 \\
\hline \multicolumn{9}{|l|}{ Parity } \\
\hline Primi & 130 & 65.7 & 50 & 25.3 & 18 & 9.1 & 198 & 61.9 \\
\hline Multi & 92 & 75.4 & 21 & 17.2 & 9 & 7.4 & 122 & 38.1 \\
\hline Total & 222 & 69.4 & 71 & 22.2 & 27 & 8.4 & 320 & 100.0 \\
\hline \multicolumn{9}{|c|}{ Gestational age } \\
\hline $37-40$ weeks & 122 & 69.3 & 40 & 22.7 & 14 & 8.0 & 176 & 55.0 \\
\hline$>40$ weeks & 100 & 69.4 & 31 & 21.5 & 13 & 9.0 & 144 & 45.0 \\
\hline Total & 222 & 69.4 & 71 & 22.2 & 27 & 8.4 & 320 & 100.0 \\
\hline
\end{tabular}


It is evident from Table 7 that incidence of fetal distress and pathological AT was found in all patients with IUGR, oligohydraminos, diabetes and PIH with IUGR.

Table 5: Risk factors in the study population.

\begin{tabular}{|l|l|l|}
\hline Risk factors & N & $\%$ \\
\hline Postdated & 120 & 37.5 \\
\hline PIH & 66 & 20.6 \\
\hline PIH with IUGR & 21 & 6.6 \\
\hline IUGR & 18 & 5.6 \\
\hline PROM & 34 & 10.6 \\
\hline BOH & 22 & 6.9 \\
\hline Oligohydramanio & 14 & 4.4 \\
\hline Diabetes & 11 & 3.4 \\
\hline Rh-ve pregnancy & 8 & 2.5 \\
\hline Others & 6 & 1.9 \\
\hline Total & 320 & 100.0 \\
\hline
\end{tabular}

Table 6: Admission test result and incidence of foetal distress.

\begin{tabular}{|l|l|l|l|l|}
\hline \multirow{2}{*}{ Results } & At results & \multicolumn{2}{c|}{ Foetal distress } \\
\hline Normal & N & \% & N & \% \\
\hline Suspicious & 222 & 69.4 & 30 & 13.5 \\
\hline Pathological & 27 & 22.2 & 19 & 26.8 \\
\hline
\end{tabular}

$\mathrm{P}<0.05^{*}$

Moderate thick meconium stained liquor (mod -thick MSL) was seen $48.1 \%$ of the patients with pathological AT as compared to $15.5 \%$ of the suspicious AT and $9 \%$ of the normal AT group $(\mathrm{p}<0.05 \%)$. The incidence of birth asphyxia in neonates with a pathological AT as evidenced by the AGPAR score 7 at 5 minute and cord blood $\mathrm{pH}<7.2$ was high, $44.4 \%$ and $29.6 \%$ respectively.

Table 7: Incidence of foetal distress (FD) in specific risk factor groups. Data are expressed as number (N) and \%.

\begin{tabular}{|c|c|c|c|c|c|c|c|c|c|}
\hline \multirow{2}{*}{ Risk factors } & \multicolumn{3}{|c|}{ Normal ( $\mathrm{N}=222$ ) } & \multicolumn{3}{|c|}{ Suspicious (N=71) } & \multicolumn{3}{|c|}{ Pathological (N=27) } \\
\hline & Total & FD $(\mathbf{N})$ & $\%$ & Total & FD $(\mathbf{N})$ & $\%$ & Total & FD (N) & $\%$ \\
\hline Postdated & 80 & 11 & 13.8 & 31 & 8 & 25.8 & 9 & 4 & 44.4 \\
\hline PIH & 41 & 4 & 9.8 & 19 & 3 & 15.8 & 6 & 3 & 50.0 \\
\hline PIH with IUGR & 12 & 3 & 25.0 & 6 & 2 & 33.3 & 3 & 2 & 66.7 \\
\hline IUGR & 11 & 3 & 27.3 & 5 & 2 & 40.0 & 2 & 2 & 100.0 \\
\hline PROM & 28 & 2 & 7.1 & 4 & 1 & 25.0 & 2 & 0 & 0.0 \\
\hline $\mathrm{BOH}$ & 18 & 2 & 11.1 & 2 & 2 & 100.0 & 2 & 1 & 50.0 \\
\hline Oligohydramanios & 11 & 2 & 18.2 & 2 & 1 & 50.0 & 1 & 1 & 100.0 \\
\hline Diabetes & 10 & 1 & 10.0 & 0 & 0 & 0.0 & 1 & 1 & 100.0 \\
\hline $\mathrm{Rh}$-ve pregnancy & 6 & 2 & 33.3 & 2 & 0 & 0.0 & 0 & 0 & 0.0 \\
\hline Others & 5 & 0 & 0.0 & 0 & 0 & 0.0 & 1 & 1 & 100.0 \\
\hline
\end{tabular}

Table 8: Correlation of foetal/neonatal outcomes with AT.

\begin{tabular}{|c|c|c|c|c|c|c|}
\hline & \multicolumn{2}{|c|}{$\begin{array}{l}\text { Normal } \\
(\mathrm{N}=222)\end{array}$} & \multicolumn{2}{|c|}{$\begin{array}{l}\text { Suspicious } \\
(\mathrm{N}=71)\end{array}$} & \multicolumn{2}{|c|}{$\begin{array}{l}\text { Pathological } \\
(\mathrm{N}=27)\end{array}$} \\
\hline & $\mathbf{N}$ & $\%$ & $\mathbf{N}$ & $\%$ & $\mathbf{N}$ & $\%$ \\
\hline $\begin{array}{l}\text { Mod-thick } \\
\text { MSL }\end{array}$ & 20 & 9.0 & 11 & 15.5 & 13 & 48.1 \\
\hline $\begin{array}{l}\text { Apgar score } \\
5 \mathrm{~min}<7\end{array}$ & 16 & 7.2 & 8 & 11.3 & 12 & 44.4 \\
\hline $\begin{array}{l}\text { NICU } \\
\text { admission }\end{array}$ & 14 & 6.3 & 8 & 11.3 & 9 & 33.3 \\
\hline $\begin{array}{l}\text { Cord blood } \\
\mathrm{Ph}<7.2\end{array}$ & 10 & 4.5 & 5 & 7.0 & 8 & 29.6 \\
\hline $\begin{array}{l}\text { Neonatal } \\
\text { death }\end{array}$ & 1 & 0.5 & 3 & 4.2 & 2 & 7.4 \\
\hline
\end{tabular}

There were five neonatal deaths in mothers with suspicious and pathological AT's, and the NICU admission was the highest in the pathological AT group (Table 8).

In comparison to pathological AT group where incidence of LSCS was $66.7 \%$, the normal AT group patients had $30.2 \%$ of LSCS while the suspicious AT group had $39.4 \%$. Instrumental delivery, forceps/vacuum application was higher in the normal AT i.e.,13.1\% while the pathological AT patients had $11.1 \%$.

The results indicate that operative/ instrumental delivery techniques with fetal distress were higher in the pathological group and considerably lower in the normal group (Table 9). 
Table 9: Mode of delivery with the results of the admission test and occurrence of foetal distress (FD).

\begin{tabular}{|l|l|l|l|l|l|l|}
\hline \multirow{2}{*}{ Mode of delivery } & Normal & $\mathbf{N}=\mathbf{2 2 2})$ & Suspicious & $(\mathbf{N}=71)$ & \multicolumn{3}{l|}{ Pathological $(\mathbf{N}=27)$} \\
\hline Spontaneous vaginal delivery & $\mathbf{N}$ & $\mathbf{\%}$ & $\mathbf{N}$ & $\mathbf{\%}$ & $\mathbf{N}$ & $\mathbf{\%}$ \\
\hline With FD & 126 & 56.8 & 38 & 53.5 & 6 & 22.2 \\
\hline Without FD & 25 & 11.3 & 12 & 16.9 & 1 & 3.7 \\
\hline Forceps/Ventouse & 101 & 45.5 & 26 & 36.6 & 5 & 18.5 \\
\hline With FD & 29 & 13.1 & 5 & 7.0 & 3 & 11.1 \\
\hline Without FD & 8 & 3.6 & 3 & 4.2 & 2 & 7.4 \\
\hline LSCS & 21 & 9.5 & 2 & 2.8 & 1 & 3.7 \\
\hline With FD & 67 & 30.2 & 28 & 39.4 & 18 & 66.7 \\
\hline Without FD & 9 & 4.1 & 13 & 18.3 & 17 & 63.0 \\
\hline P $<0.05$ & 58 & 26.1 & 15 & 21.1 & 1 & 3.7 \\
\hline
\end{tabular}

$\mathrm{P}<0.05$

The above table shows that AT CTG has high sensitivity and specificity for predicting fetal distress $(53 \%$ and $75 \%$ respectively). The proportion of the false negatives were low. A high NPV $(86.49 \%)$ enables a clinician to accurately exclude fetal distress in an individual patient.

Table 10: Diagnostic parameters of admission test.

\begin{tabular}{|l|l|}
\hline & Present study \\
\hline Sensitivity & 53.13 \\
\hline Specificity & 75.00 \\
\hline Positive predictive value & 34.69 \\
\hline Negative predictive value & 86.49 \\
\hline False negatives & 9.4 \\
\hline False positives & 20.00 \\
\hline
\end{tabular}

\section{DISCUSSION}

The admission CTG is a simple noninvasive tool. It can be used as a screening test in early labor to detect compromised fetuses on admission and thereby select the women in the need of continuous EFM during labour.A Cochrane based review recommended the use of continuous EFM be limited to high risk pregnancies where antenatal care is inadequate with a large number of high risk pregnancies being delivered in crowded settings and inadequate low health care provider to patient ratio. ${ }^{12}$ In developing countries like India where this study was conducted this is applicable because of the high patient input in the labour rooms and the paucity of CTG monitors. The use of EFM is controversial in intrapartum monitoring. In an RCT conducted by Impey et al found no role of admission CTG in improving the neonatal outcome. Similarly, Blix et al, in a systemic review of three randomized controlled trial found that labour admission CTG has no prognostic value. ${ }^{13}$ In contrast Akhavan et al showed that the AT was a useful screening tool in patients with high risk factors and was able to predict neonatal outcomes in terms of NICU admission and the need for caesarean birth. ${ }^{14,15}$ Hafizur et al, had a $57.1 \%$ of NICU and cesarean birth rate as high as $100 \%$ with an ominous AT and with fetal distress. Blessy D17 et al conducted a study on 400 women and the incidence of caesarean delivery with non-reactive AT was $93.25 \%$ and the same group had $43.7 \%$ babies in the NICU. ${ }^{16,17}$ This is consistent with the present study where pathological AT group births had $33.3 \%$ of NICU admission as compared $6.3 \%$ of the normal AT group births. The rate of caesarean section in the current study is $66.7 \%$ in the pathological AT group. The present study has $55.6 \%$ of the pathological AT in high risk patients as in the studies of Behuria et al and Sandhu et al and Das et al. Behuria S, study shows fetal distress in high risk patients was found in $64 \%$ of the nonreactive cases whereas Ingemarsson et al 8 study in low risk patients had fetal distress in $40 \%$ of the reactive group. ${ }^{8,18}$ Sandhu et al found a $73 \%$ fetal distress in high risk patients with a non-reactive AT. Das V et al, found fetal distress in $31.5 \%$ of high-risk patients of the reactive category and in $18.8 \%$ in the low risk category. ${ }^{19,20}$ Incidence of fetal distress in this study is high in this study due to the recruitment of only high-risk cases and exclusion of low risk cases. Gourounti et al, have done a meta -analysis of different RCT's (randomized controlled trial) and have found increase rate of caesarean section and instrumental delivery in low risk patients with an AT. However, in the present study where only high-risk patients were included also showed an increase rate of caesarean section and instrumental delivery in patients with both suspicious and pathological AT 's. ${ }^{21}$ In Libirian et al study ,50\% risk of fetal asphyxia was reported in the ominous group babies when measured by APGAR score and /umbilical cord blood $\mathrm{pH}$. In this study, the cord blood $\mathrm{pH}<7.2$ in the neonates was higher $29.6 \%$ in the pathological AT group as compared to $4.5 \%$ in the normal AT group .Both the present and Libirian et al study were in agreement. ${ }^{22}$ Panda et al study on the efficacy of admission CTG to predict obstetric outcome obtained a sensitivity of 57.89 $\%$, specificity of $96.30 \%$, a PPV of $78.5 \%$, NPV of $90.70 \%$ but in present study had a sensitivity of $53.13 \%$, specificity $75 \%$, PPV of $34.69 \%$ and an NPV of $86.49 \%$. The difference in specificity may be due to the selection of only high-risk cases. Amena Kaur et al got a statistically non-significant data in the abnormal NST and meconium stained liquor. The study of Santosh et al 
evaluated 200 patients with the AT and reported that the incidence of meconium stained liquor, need for NICU admission was was significant statistically and is in agreement with present study $(\mathrm{p}<0.05) .^{23,24,25}$

\section{CONCLUSION}

The admission test cardiotocography is a simple, noninvasive, inexpensive test for both antepartum and intrapartum fetal wellbeing assessment. It should be used as a screening test modality to differentiate high risk patients from low risk patients. This study emphasis on the role of AT in planning early intervention as majority of the patients with a pathological tracing landed up in caesarean delivery .It also prevents neonatal morbidity and mortality as the high NPV (98.7\%) of the study reflects on the importance of AT in identifying a compromised fetus. The load of continuous monitoring in high risk patients can be decreased thus proving to be a time saving method in intervention required especially in institutes with a high patient load.

\section{Funding: No funding sources}

Conflict of interest: None declared

Ethical approval: The study was approved by the Institutional Ethics Committee

\section{REFERENCES}

1. Whittle MJ, Martin WL.Foetal monitoring in labor. In: Chamberlain G, steer P,editors Turnbull's obstetrics. London: Churchill Livingstone; 2001.

2. Gibb D, Arulkumaran S. Oxford: Boston: ButterworthHeinemann; 1997. The admission test: Clinical scenario Foetal monitoring in practice. pp. 67-72.

3. Chandraharan E, Sabaratnam A. Electronic foetal heart rate monitoring in current and future practice. J Obstet Gynecol India. 2008;58(2):121-30.

4. Thackar SB, Struup DF. Continuous electronic heart rate monitoring for foetal assessment during labor. Cochran Database Syst Rev. 2001;(2)CD000063.

5. Freeman RK, Garite TJ, Nageotte MP, Miller LA. History of fetal monitoring. Fetal heart rate monitoring (Eds: Freeman RK, Garite TJ). William and Wilkins, Baltimore. 1981:1-6.

6. Lekis S, Loghis C, Parayoto N. Use of antepartum and intrapartum cardiography. Clin Exp Obstet Gynaecol. 1997;24:79-81.

7. Schifrin BS, Foye G, Amato J, Kates R, MacKenna J. Routine foetal monitoring in the antepartum period. Obstet Gynecol. 1979;54(1):21-5.

8. Ingemarsson I, Arulkumaran S, Ingemarsson E, Tambyraja RL, Ratnam SS. Admission test: a screening test for fetal distress in labor. Obstet Gynecol. 1986;68(6):800-6.

9. Ingemarsson I. Electronic fetal monitoring as a screening test. Intrapartum Fetal surveillance. London: Royal College of obstetricians and Gynaec. 1993.
10. Prentice A, Lind T. Foetal heart rate monitoring in labour - too frequent intervention, too little benefit? Lancet. 1987;2(8572):1375-7.

11. National Institute for Health and Clinical Excellence, NICE Clinical Guideline 190.1 - Intrapartum Care. Feb, 2017. pp. 10-13.

12. Impey L, Reynolds M, MacQuillan K, Gates S, Murphy J, Sheil O. Admission cardiotocography: a randomised controlled trial. The Lancet. 2003;361(9356):465-70.

13. Blix E, Reinar L M, Klovning A, Oian P. Prognostic value of the labor admission test and its effectiveness compared with auscultation only: A systematic review. Br J Obstet Gynaecol. 2005;112(12):1595-604.

14. Blessy D, K Saraswathi. A study on role of admission CTG as a screening test to predict fetal outcome. Res J Pharm, Biol Chem Sci Obstet Gynaecol. 2014;5(6):295.

15. Akhavan S, Lak P, Rahimi-Sharbaf F, Mohammadi SR, Shirazi M. Admission Test and Pregnancy Outcome. Iranian J Med Sci. 2017;42(4):362-8.

16. Rahman H, Prachi R, Sudip D. Reliability of admission cardiotocography in predicting adverse perinatal outcome in low risk obstetric population. Indian Obstet Gynaecol. 2012;2(4).

17. Behuria S, Nayak R. Admission cardiotocography as a screening test in high risk pregnancies and its corelation with peri-natal outcome. Int $\mathbf{J}$ Reprod Contracept Obstet Gynecol. 2016;5(10):3525-8.

18. Sandhu GS, Raju R, Bhattacharyya TK, Shaktivardhan. Admission Cardiotocography Screening of High-Risk Obstetric patients. Medical J Armed Forces India.2008;64(1):43-45.

19. Das V, Katiyar N, Malik GK. Role of admission test. J Obstet Gynecol Ind. 2001;51(1):48-50

20. Gourounti K, Sandall J. Admission cardiotocography versus intermittent auscultation of fetal heart rate: effects on neonatal Apgar score, on the rate of caesarean sections and on the rate of instrumental delivery - a systematic review. International J Nursing Studies. 2007;44(6):1029-35.

21. Libiran MJ, Solis MS, Santos RR, Baga EB. Admission test as predictor of intrauterine fetal asphyxia. Philippine J Obstet Gynecol: Official publication, Philippine Obstet Gynecol Soc. 1999;23(4):143-9.

22. Panda S, Das A, Nowroz HM, Singh AS. Role of Admission Tests in Predicting Perinatal Outcome: A Prospective Study. J Preg Child Health. 2015;2(171):2.

23. Khatun A, Khanam NN, Nazir F. Role of Elaborate Cardiotocography (CTG) in Pregnancy Management. Bangabandhu Sheikh Mujib Medical University J. 2009;2(1):18-24.

24. Bhangdiya S, Dadhe K, Khatod L. Labor admission test (cardiotocography) as intrapartum risk screening test and its efficacy to predict fetal outcome. Int $\mathrm{J}$ Rec Trend Sci Technol. 2015;16:459-62.

Cite this article as: Kumar A, Jaju PB. Admission test cardiotocography in labour as a predictor of foetal outcome in high risk pregnancies. Int J Reprod Contracept Obstet Gynecol 2019;8:1331-6. 